\title{
Interpreting focus again
}

BART GEURTS \& ROB VAN DER SANDT

How to respond to such a fine collection of commentaries which are, without exception, thorough, to the point, constructive, and full of suggestions for improvement? The best response by far would be a radical overhaul of the target article - but that is against the rules. The next-best thing would be a page-by-page discussion of each commentary separately - which the editor wouldn't allow. So we have no choice but to make a selection of the many good points that have been raised, and hope against hope that we will manage not to distort them too much.

The plan for the following discussion mirrors that of 'Interpreting focus' (IF). So we start with the main issue, concerning the association between focus and presupposition, then turn to focus particles, and conclude with a few remarks on it-clefts.

\section{Promiscuous bindees}

One of the central tenets of IF was formulated as follows:

The main prediction that the BPR gives rise to [...] is that focusing should cause the projection behaviour that is characteristic of definite noun phrases, factive verbs, and the like.

Most of the commentators express reservations about this claim, and several present data intended to refute it, such as the following:

(1) a. (My team didn't score a goal.) Did the others $\mathrm{F}_{\mathrm{F}}$ score a goal? (Büring) 
b. (Did anybody eat the beans?) Yes, Fred $F_{F}$ ate the beans. (Kratzer)

Intuitively, the backgrounded material in these examples serves to link up to information in the preceding discourse that would be inaccessible to ordinary presuppositions. Hence our claim that focusing causes projection behaviour must be false. As Kratzer puts it, '[t]he inferences contributed by backgrounding just don't seem to behave like run-of-the-mill presuppositions. They project and compose differently.'

This objection is based on the premiss that we are out to defend what Büring calls the 'Uniformity Hypothesis':

\section{Uniformity Hypothesis}

The accessibility requirements for antecedents for the focus supposition $\mathrm{P}$ equal those for the antecedent of Ordinary Presuppositions as introduced by the, too, regret, stop, also, it-clefts etc. etc.

There is an unfortunate misunderstanding here, which must be due to our wording of the claim that focusing causes projection behaviour. As illustrated by Büring's Uniformity Hypothesis, our claim has been taken to entail that all presuppositions project in the same way, but as we argue at various points in IF (though not, alas, in the vicinity of the passage cited above), that is not the case. To be sure, the principles governing presupposition projection are always the same. But individual presuppositions vary along two dimensions at least. First, due to differences in form or content, some presuppositions are easier to accommodate than others. Secondly, some presuppositions bind to inaccessible positions and give rise to fully transparent construals, while others don't.

Hence, a better way of expressing our empirical claim is as follows:

Given that there is a range of variation in the projection behaviour of presuppositions, the behaviour displayed by backgrounded material falls within that range.

If this is correct, as we maintain it is, the proposed explanation is that the projection mechanism underlying presupposition is operative in the interpretation of backgrounded information, as well.

Both Jäger and Schwarzschild point out that the proper treatment of examples like $(1 \mathrm{a}-\mathrm{c})$ follows naturally from our analysis of 'too'. We ar- 
gued that the presuppositions associated with additive focus particles ('too', 'also', 'even', 'again') have a somewhat special structure which allows them to bind in positions that are formally inaccessible from the positions in which they arise. Schwarzschild observes that this is a characteristic of focus presuppositions in general (cf. also Schwarzschild 1999). Jäger illustrates the point with respect to the contrastive phrases in (2).

(2) Maybe $\mathrm{John}_{\mathrm{F}}$ yelled, and maybe Bill $\mathrm{F}$ yelled.

In both $(1 \mathrm{a}-\mathrm{c})$ and (2) the focus presuppositions may, within the framework of our theory, be bound to a formally inaccessible antecedent since the resulting DRS is non-defective. ${ }^{1}$ So, taking into account Jäger's and Schwarzschild's observation, our theory turns out to actually explain why it is that in cases like (1a-c) and (2) focus presuppositions may be bound in positions that are inaccessible to most other presuppositions.

The inferences licensed by the BPR are, in Schwarzschild's happy phrase, 'promiscuous bindees'. This partly accounts for Kratzer's intuition that focus presuppositions are 'expressive meanings'. Focus presuppositions fit Kratzer's description of expressive meanings in that they don't care very much about the accessibility restrictions that most other presuppositions have to obey. According to Kratzer, however, 'a characteristic property of expressive meanings is that, once computed, they cannot participate in any further processes of meaning composition,' and in our view this is not a characteristic of focus presuppositions. In conjunction with our theory of presupposition projection, the BPR predicts that focus presuppositions are promiscuous bindees that will affect truthconditional content in certain cases (e.g. by restricting the domain of a quantifier).

\section{The status of the BPR}

In our formulation of the BPR we went out of our way not to say that focusing 'triggers' presuppositions, explaining in a footnote $(n .10)$ that

1 There are cases in which a focus presupposition contains discourse referents that become free when the presupposition is bound in an inaccessible position, but such cases are the exception rather than the rule (see below). 
we prefer to avoid this locution because we are not convinced that the relation between focus and presupposition is in all respects the same as that between grammatical (i.e. lexical or syntactic) presupposition triggers and their presuppositions, for which these terms are commonly used. Our admittedly informal characterisation of the connection between backgrounds and presuppositions was that since focusing serves to evoke set of alternatives, it is plausible to assume that there is a general presumption to the effect that, in any given case, one of these alternatives holds. This only the beginning of an explanation, of course, and it is one of the parts of our theory that needs more work.

Jacobs's commentary may be seen as addressing this issue (though this is not how he views it; see below). Jacobs discusses the relation between the BPR and a discourse rule he dubs the BDR:

\section{The Background-Discourse Rule (BDR)}

If an utterance $u^{s}$ of a sentence $s$ has a free [focus background structure] that gives rise to a background $\lambda x[\varphi(x)]$, then $u^{s}$ is felicitous only if $\lambda x[\varphi(x)]$ has already been under discussion in the relevant stretch of discourse preceding $u^{s}$.

The BDR accounts for the well-known observation that the focus position in an answer correlates with the wh-phrase in the backgrounded question, and may be used to derive the default of existential inference for focal backgrounds from a rather uncontroversial assumption, namely that a question presupposes that at least one of its possible answers is true. This assumption is an essential feature in the theories of Hintikka (1976) and Belnap and Steel (1976), and is adopted, implicitly or explicitly, in much subsequent theorising on questions.

The assumption that questions have existential import predicts (for free focus-background structures) that existential import comes about in an indirect way: the existential presupposition we observe derives from the backgrounded question. However, as Jacobs points out, this view is problematic for the simple reason sequences like the following are fully acceptable:

(3) Has anybody invited Gerda? Peter ${ }_{F}$ invited Gerda.

Here the existential import of focusing cannot be attributed to the preceding question, evidently. It was observations like this that led us to remain non-committal as to the origin of focus presuppositions. 
Incidentally, we disagree with Jacobs's view on sentences in (4):

(4) a. If Peter ${ }_{F}$ invited Gerda to the party, she will certainly come

b. If my information is correct, then Peter $_{\mathrm{F}}$ invited Gerda to the party.

Jacobs observes that these sentences may be felicitously uttered in the context of (5), and takes this to imply that they don't come with existential presuppositions.

(5) Do you know whether Gerda was invited to the party?

In our opinion, $(4 a-b)$ do have existential import. This inference may seem to be 'suspended' in the context of (5), but that is due to the fact that the focus presuppositions link up to the embedded question.

We concede that, as it stands, the BPR is stipulative and will have to be motivated somehow, perhaps by recourse to general discourse principles such as BDR. However, Jacobs goes on to suggest that such principles are bound supplant the BPR, and in this respect our views differ. The crucial observation is that the inferences triggered by focusing appear to exhibit projection behaviour. Jacobs acknowledges that they do, and gives a 'rough sketch' as to how this behaviour can be accounted for, but it must be said that his sketch are very rough indeed. We don't want to exclude the possibility that Jacobs's programme may be carried through, but in default of a more detailed explanation, a theory of focus interpretation will have to fall back on a mechanism of presupposition projection, or else significant regularities will remain unaccounted for.

\section{Beyond copy and paste}

In IF we implemented the BPR as a copy-and-paste procedure without paying proper attention to technical details, and it is only fair that Jäger and Schwarzschild should take us to task for this. Having been forced to look harder we now see that the issue is hairier than we assumed when we wrote our paper, and we are not out of the wood yet. But we are inclined to take Jäger's advice, which we interpret as follows. The way we formulated it, the BPR associates with each background $\lambda x . \varphi(x)$ a presupposition to the effect that $\lambda x . \varphi(x)$ holds of some entity of the appropriate 


\section{Bart Geurts \& Rob van der Sandt}

type. We have realised in the meantime that implementing this idea becomes a lot easier if we use $\lambda$-terms in the DRS-language, as well, so that is what we will do. That is, we now represent backgrounded material by a $\lambda$-abstract that takes focused material as an argument. Here is an example: ${ }^{2}$

(6) Beryl always drinks sherry .

(7) $\left[\mathrm{x}: \operatorname{Beryl}(\mathrm{x}),[\mathrm{e}:]\langle\forall \mathrm{e}\rangle\left[: \lambda \mathrm{y}\left[: \mathrm{x}\right.\right.\right.$ drinks $\left._{\mathrm{e}} \mathrm{y}\right]($ sherry)$\left.]\right]$

Jäger recommends that all and only discourse referents that are introduced within a background should be relabeled when a copy is made. Having $\lambda$-terms available, we can implement this by simply making a verbatim copy of the $\lambda$-term, and applying it to a fresh discourse referent. For the example in (6), this yields the DRS in (8a):

(8) a. [x: $\operatorname{Beryl}(x)$,

[e: $]\langle\forall \mathrm{e}\rangle\left[\underline{\mathrm{z}}: \underline{\lambda y}\left[: \underline{\mathrm{x} d r i n k s} \mathrm{~s}_{\mathrm{z}} \mathrm{y}\right](\underline{\mathrm{z}}), \lambda \mathrm{y}\left[: \mathrm{x} \operatorname{drinks}_{\mathrm{e}} \mathrm{y}\right](\right.$ sherry)$\left.)\right]$

b. $[\mathrm{x}: \operatorname{Beryl}(\mathrm{x})$,

$[\mathrm{e}, \mathrm{z}: \lambda \mathrm{y}[: \mathrm{x}$ drinks $\mathrm{y}](\mathrm{z})]\langle\forall \mathrm{e}\rangle\left[\lambda \mathrm{y}\left[: \mathrm{x}\right.\right.$ drinks $\left._{\mathrm{e}} \mathrm{y}\right]($ sherry)$\left.]\right]$

The underlined presupposition in (8a) cannot be bound, nor can it be accommodated in the main DRS, because that would cause a free occurrence of the event variable e. Therefore the presupposition is accommodated in the restrictor of the adverbial quantifier.

If we adopt this procedure, any discourse referents within a background that are introduced outside of it are not reintroduced. In the example above, $u$ and e are not reintroduced, the former because it is part of a presupposition triggered by the name 'Beryl' which goes to the main DRS, the latter because it is bound by the adverbial quantifier. This is to say that any presupposition-inducing expressions within a background (including pronouns) must be processed before the BPR applies.

\section{Only}

According to the interpretation given in (8b), (6) says that whenever Beryl drinks something, she drinks sherry. It does not exclude the possibility

2 (6) occurs in IF as example (26), and the following analysis is the same as that given in IF; $\lambda$-terms are merely a convenient tool for making the procedure more transparent. 
that whenever Beryl drinks something, she drinks sherry and something else (milk, say). Schwarzschild seems to think this may be a problem, ${ }^{3}$ but it isn't. Beaver and Clark (2003) observe that a sentence like (6) doesn't entail that Beryl drinks nothing but sherry, as witness the fact that the following is consistent (cf. also the commentaries by Beaver and Kratzer):

(9) Beryl always drinks sherry $y_{F}$, though she sometimes drinks milk as well.

Beaver and Clark point out that 'always' and 'only' are strikingly different in this regard, as the contrast between (9) and (10) illustrates:

(10) *Beryl only drinks sherry , though she sometimes drinks milk as well.

How can this contrast be accounted for? The answer, we believe, lies in the rather obvious fact that 'always' binds the event variable associated with the verb, while 'only' does no such thing. To illustrate, we suggest that the initial DRS for (11) is something along the lines of (12a):

(11) Beryl only drinks sherry .

(12) a. $\quad\left[x: \operatorname{Beryl}(x), \neg\left[y: \lambda z\left[e: x \operatorname{drinks}_{\mathrm{e}} \mathrm{z}\right](\mathrm{y}), \mathrm{y} \neq\right.\right.$ sherry $\left.]\right]$

b. $\quad\left[x: \operatorname{Beryl}(x), y^{\prime}: \lambda z\left[e: x\right.\right.$ drinks $\left._{\mathrm{e}} \mathrm{z}\right]\left(\mathrm{y}^{\prime}\right)$,

$\neg[y: \lambda z[e: x$ drinks $\mathrm{z}](y), y \neq$ sherry $]]$

In the initial DRS for the example with 'always' in (8a), the event variable in the background is bound from outside, by the adverbial quantifier. In (12a), by contrast, the event variable is introduced within the background, so the BPR yields a presupposition of the form $\left[y^{\prime}: \lambda z[e: x\right.$ drinks $\left.\mathrm{z}]\left(\mathrm{y}^{\prime}\right)\right]$. The presupposition ends up being accommodated in the main DRS, yielding (12b). Unlike its counterpart in (8b), this DRS entails that Beryl drinks sherry and nothing but sherry. Hence the difference between 'always' and 'only' is explained simply by assuming the obvious, viz. that the lexical meaning of 'always' involves event-like entities, while that of 'only' does not. The resulting analysis is rather less contrived than Beaver and Clark's.

3 More precisely, Schwarzschild suggests that if there is a requantification problem (which he doubts, apparently), (6) would be an instance. (Schwarzschild's example (13) has 'a martini' instead of 'sherry' but the point remains the same.) 
In our discussion of 'only' we argued at some length that 'only' is not a strong quantifier, presupposing that it makes sense to ask if 'only' is strong or weak. Beaver and Eckardt raise doubts about this presupposition. Eckardt considers the discussion 'not very helpful'; Beaver (forthright as ever) calls it a 'bogus issue'. We still believe there is a real issue here, so let us try to get it into the open. According to Horn (1996), 'only' is a reversed universal quantifier (Beaver and Clark follow Horn in this respect). Putting it more bluntly than Horn would ever do, 'Only A is B' means the same as 'Every B is A'. Now it so happens that 'Only A is B' and 'Every $\mathrm{B}$ is $\mathrm{A}$ ' are alike in that they have existential import: both sentences imply that B is non-vacuous. This is not an accident, in Horn's view: 'Only A is B' has existential import, he claims, because 'only' is a universal quantifier.

In IF we elaborated on Horn's analysis in two ways, both of which seemed entirely natural to us. First, having argued that 'Only A is B' presupposes that $\mathrm{B}$ is non-empty, and accepting the widely held opinion that 'Every B is A', too, presupposes that B is non-empty, we read Horn's 'has existential import' as 'triggers an existence presupposition'. Secondly, since the existence presupposition of 'every' and its kin correlates with the fact that they are strong quantifiers, the question we raised was: Is it true that the existential presupposition associated with 'only' is due the fact that it is a strong quantifier? Our answer to this question was, and still is, no: 'only' is weak and its presupposition is due to the BPR.

We hope that the foregoing remarks will at least convince our critics that our way of framing the issue makes sense. Whether our attempts at resolving it cut any ice is a different matter altogether.

\section{Too}

Eckardt uses the following example to argue that our analysis of 'too' is insufficiently constrained:

(13) ?There is Fred, and Barney $y_{F}$ is staying at the Ritz, too.

Eckardt observes that (13) is infelicitous and that our theory fails to explain why it should be. And she is right on both counts. According to our analysis, 'too' triggers a double-barreled presupposition: first there 
is an anaphoric presupposition which requires that some individual $\mathrm{x}$, $\mathrm{x} \neq$ Fred, be contextually given, and then there is a more substantive presupposition saying that $\mathrm{x}$ is staying at the Ritz. The first presupposition may be linked to Fred, and the second one may be accommodated (assuming, of course, that no further contextual information is available).

We agree that (13) is infelicitous and that our theory of 'too' doesn't explain why. But, we submit, it is not all obvious that a theory of 'too' should explain why (13) is infelicitous. (13) is incoherent, it is true, but so is the following:

(14) ?There is Fred, and his dog eats olives.

Furthermore, (13) improves a great a deal if we insert a speaker's turn in the middle:

(15) A: There is Fred.

$\mathrm{B}$ : $\mathrm{O}$, that reminds me: did you know that Barney $\mathrm{F}_{\mathrm{F}}$ is staying at the Ritz, too?

As our account leads us to expect, B's utterance suggests rather strongly that Fred is staying at the Ritz, as well.

Whatever it is that makes (13) awkward, we are not convinced that the contribution of 'too' is an essential part of the explanation. However, the conclusion which Eckardt seeks to establish is correct: our theory of 'too' is incomplete. This is shown by observations made by Büring, Kratzer, and Schwarzschild:

(16) ?Fred is not staying at the Ritz and Barney $y_{F}$ is staying there too. (Schwarzschild)

(17) Sue doubts that Ed attended the meeting, but we all agree that Jill attended the meeting (?too). (Kratzer)

(18) (Sue thinks Bob married Christie.) Does Steve think Bob (?also) married Nana ? (Büring)

The examples by Schwarzschild and Kratzer suggest that the presupposition associated with 'too' cannot bind to an antecedent in a non-veridical environment (Giannakidou 1998). Büring's example may be taken to show, as he himself suggests, that additive focus particles like 'also' and 'too' imply (by way of conventional implicature, perhaps) that it is at 
least possible for the matrix sentence and the antecedent proposition to be true together: with 'also' (18) is odd, it seems, because Bob cannot be married to two women at the same time. (He can in a polygamous society, but there the sentence wouldn't be odd.)

The foregoing observations do not refute our analysis of 'too'. For the time being, they merely show that it is incomplete. On reflection, this is not so remarkable. As argued by Kripke (ms) and Asher and Lascarides (1998), it is rather plausible that 'too' requires a relation of parallelism between two propositions, and the constraints imposed on this relation by our analysis are very weak indeed. It remains to be seen, however, if and how our constraints can be strengthened to yield a better theory.

\section{It-clefts}

Gawron, Jäger, and Schwarzschild discuss Rooth's (1999) argument against an existential semantics for focus (i.e. the BPR), which uses examples like the following:

(19) A: Did anyone win the football pool this week?

B: ?Probably not, because it's unlikely that it's Mary F $_{\text {, wo }}$ it, and she's the only person who ever wins.

$B^{\prime}$ : Probably not, because it's unlikely that Mary $y_{F}$ won it, and she's the only person who ever wins.

In order to explain why (19B) is awkward, Rooth assumes that the existential presupposition triggered by the $i t$-cleft projects to the main DRS (the terminology is ours, not Rooth's). So the speaker presupposes that someone won the football pool, thus contradicting his own statement that he doesn't know if someone won the football pool, and therefore the sentence is odd. Now if the backgrounded material in $\left(19 \mathrm{~B}^{\prime}\right)$ triggered a presupposition, the sentence should be infelicitous, too. But in fact it is fine, so there can't be an existential presupposition in $\left(19 \mathrm{~B}^{\prime}\right)$.

Rooth's argument depends on the assumption that if we adopt the BPR, sentences like (19B) and $\left(19 \mathrm{~B}^{\prime}\right)$ will the same in all relevant respects; in particular, they will have the same presuppositions. In IF we sought to undermine this assumption by arguing that $i t$-clefts differ from plain focus-background sentences because they contain anaphoric pro- 
nouns (i.e. descriptively attenuate presupposition inducers). Put otherwise: clefts are different because, contrary to what is often assumed, the pronouns they contain are not expletives. If this much can be shown, Rooth's argument collapses.

In an attempt to show that cleft pronouns are anaphoric, we pointed out that they alternate with demonstratives:

$$
\{\text { It/This/That }\} \text { was Fred we just saw. }
$$

Gawron objects against this argument, noting that in English 'this' and 'that' cannot always substitute for cleft pronouns:

$\left\{\mathrm{It} /{ }^{*}\right.$ This/*That $\}$ was from Fred that he borrowed the racket.

Gawron concludes from this observation that 'there seems to be at least one [cleft] construction that does require an expletive 'it" - at least one construction, that is, for which Rooth's argument goes through.

In our opinion, Gawron's conclusion is not warranted by his observation. This is not to say that we are convinced that our view on cleft pronouns is correct. It is merely to say that, as things stand, there is no conclusive evidence for either position, because there are too many uncertainties regarding the grammar of $i t$-clefts. Gawron suggests that the grammar of the 'this' and 'that' variants of (20) may be different from that of the 'it' variant, but we consider this a moot point. Gawron also suggests that the structure of (21) may be special, which would be in line with Dik's (1980) diagnosis, but as far as we know there is no consensus on this matter, either. Nor is there consensus on the question how clefts relate to copula sentences, for example. If so much is unclear, the issue is bound to remain moot for the time being. But it is safe to say, we believe, that there is reasonable doubt about the expletive hypothesis, hence room for exploring alternatives - which is all we need for our purposes.

Returning to the minimal pair in (19), and supposing that cleft pronouns are anaphoric, how can we account for the difference in acceptability between B's cleft sentence and the non-cleft uttered by $\mathrm{B}^{\prime}$ ? According to Gawron and Jäger, our position is that there is local accommodation in the first case and accommodation failure in the second, the difference being due to the fact that $i t$-cleft presuppositions are generally harder to accommodate. There are problems with this approach, as 
Gawron and Jäger show, if only because intuitively the focus of B's answer should be linked to A's question.

Our hypothesis is that, for the reasons given above, cleft presuppositions are difficult to accommodate. But this in itself does not yield a full explanation of the contrast between clefts and non-clefts. The picture is rounded out by Schwarzschild's observation that, on our account, focus presuppositions are promiscuous bindees, whilst cleft presuppositions are not. To explain this, let us look at a simple example first: ${ }^{4}$

(22) a. It was Fred F $_{\mathrm{F}}$ who sneezed.

b. $\quad[\mathrm{x}: \operatorname{Fred}(\mathrm{x}), \underline{\underline{z}}$ : sneezed $(\mathrm{z}), \mathrm{z}=\mathrm{x}]$

(23) a. Fred $_{\mathrm{F}}$ sneezed.

b. $\quad[x: \operatorname{Fred}(\mathrm{x}), \lambda \mathrm{y}[: \operatorname{sneezed}(\mathrm{y})](\mathrm{x}), \underline{\mathrm{z}}: \underline{\lambda y}[: \underline{\operatorname{sneezed}}(\mathrm{y})](\underline{\mathrm{z}})]$

The double underlining of $z$ in (22b) is motivated by our hypothesis that the cleft pronoun is anaphoric. The crucial difference between (22b) and (23b) is this. The presuppositional material in (22b) cannot be bound because the resulting DRS will contain a free occurrence of $z$. The presupposition in (23b), by contrast, could be bound to a formally inaccessible antecedent without causing the DRS to be defective. In brief, while focus presuppositions are promiscuous bindees, cleft presuppositions are like the presuppositions triggered by definite descriptions, for example, in that they introduce discourse referents which reappear in the non-presuppositional matrix.

The complete story of the contrast in (19) goes as follows. Being a promiscuous bindee, the focus presupposition in $\mathrm{B}^{\prime}$ can be bound either within the context of A's question or, as Schwarzschild suggests, within the propositional content conveyed by 'probably not'. Either way, the presupposition is bound in a formally inaccessible position, which is not an option for the cleft presupposition in B. The latter can only be interpreted by way of accommodation, which is problematic because it contains a presupposition that is descriptively attenuate. Whence the contrast in acceptability between the two sentences.

4 In (22b), the contribution of the BPR is not shown, because it is obviated by the cleft presupposition. 


\section{References}

Asher, N. and A. Lascarides, 1998: The semantics and pragmatics of presupposition. Journal of Semantics 15: 239-300.

Beaver, D. I. and B. Clark 2003: 'Always' and 'only': why not all focus sensitive operators are alike. Natural Language Semantics 11: 323-362.

Belnap, N. D. and T. B. Steel 1976: The Logic of Questions and Answers. Yale University Press, New Haven.

Dik, S. C. 1980: Studies in Functional Grammar. Academic Press, London.

Giannakidou, A. 1998: Polarity Sensitivity as (Non) Veridical Dependency. Benjamins, Amsterdam.

Hintikka, J. 1976: The semantics of questions and questions of semantics. Acta Philosophica Fennica 28.

Horn, L. R. 1996: Exclusive company: 'only' and the dynamics of vertical inference. Journal of Semantics 13: 1-40.

Kripke, S. ms.: Remarks on the formulation of the projection problem. Princeton University.

Schwarzschild, R. 1999: GIVENness, AvoidF and other constraints on the placement of accents. Natural Language Semantics 7: 141-177.

Rooth, M. 1999: Association with focus or association with presupposition? In: P. Bosch and R. van der Sandt (eds.), Focus: Linguistic, Cognitive, and Computational Perspectives. Cambridge University Press. Pp. 232-244. 
Brought to you by | Radboud University Nijmegen (Radboud University Nijm Authenticated | 172.16.1.226

Download Date | 7/11/12 12:04 PM 